\title{
Factors influencing the use of coconut oil by the householders in Sri Lanka and their policy relevance to popularize the consumption of coconut oil
}

\author{
T. S. G. Peiris ${ }^{1}$, M. T. N. Fernando ${ }^{2}$ and S. Samarajeewa ${ }^{2}$
}

\begin{abstract}
In recent past the concept on the use of coconut oil (CNO) by the householders in Sri Lanka has been changing due to various reasons. The reasons were studied using the generalized linear models for the survey conducted during May/June 2001 for 366 householders representing three different population sectors (urban, rural and estate) and different income groups. The significant factors influencing the use of $\mathrm{CNO}$ are the type of oil used in past, monthly income, quality of $\mathrm{CNO}$, misconception about $\mathrm{CNO}$ and the population sectors. The percentage of non-CNO users is considerably higher in the urban sector, whereas CNO still is the major edible oil in the rural and estate population sectors of Sri Lanka. The percentage of householders using CNO in the sample was 91.2 . In $75 \%$ of the sample, the quantity of $\mathrm{CNO}$ consumption per person has reduced over the last five years. The main reason for dissatisfaction for $\mathrm{CNO}$ is adulteration. The proportion of $\mathrm{CNO}$ use was significantly higher in lower income groups than the higher income groups. The proportion of the CNO use decreased sharply when the income increases above Rs. 40,000 per month. The high-income earners have shifted their preferences towards other edible oil consumption. The findings of this study suggest that the growth of the per capita incomes and the rapid urbanization in the country further reduces the consumer demand for coconut oil, unless there are effective marketing strategies implemented to promote the CNO consumption in the long run. Both the proportion and rate of $\mathrm{CNO}$ use can be increased through an effective campaign via media. Improving the quality and dispelling the misconception among the householders would give better prospects to the coconut oil industry in Sri Lanka.
\end{abstract}

Key words: Coconut oil, policy issues, logistic regression and logit.

1. Biometry Division, Coconut Research Institute (CRI), Lunuwila 61150, Sri Lanka (Email: tsgp.cri.lk))

2. Agronomy Division, Coconut Research Institute (CRI), Lunuwila 61150, Sri Lanka (agronomy@cri.lk) 


\section{Introduction}

Sri Lankan householders have been using coconut oil (CNO) for cooking purpose for centuries. However, there have been various "myths" on the use of CNO during the recent past. Also the reduction of import duty on substitute oils to $\mathrm{CNO}$ in the last two decades resulted in importing substitute oils for more than double the national per capita requirements (Peiris and Fernando, 2000). Consequently, many other substitute vegetable oils are readily available at relatively lower prices at the domestic market. Even though, $\mathrm{CNO}$ has been used as the main edible oil in Sri Lanka for thousands of years, this may attract the consumers towards other edible oil consumption by changing their tastes and preferences away from CNO. Therefore, the objective of the present study is to identify the socio-economic and other inherent factors on the use of CNO by the householders in urban, rural and estate population sectors of Sri Lanka.

\section{Material and methods}

\section{The sample survey}

A household survey was conducted during May and June 2001 to obtain the necessary information through a pre-tested structured questionnaire. The sample design was two-stage stratified random sampling. Three divisional secretaries divisions (DSD) from each district of Colombo, Kurunegala and Nuwara-Eliya in Sri Lanka were purposely selected to represent urban, rural and estate population sectors respectively as the first stage of stratification. The monthly income of the respondents was the second stage of stratification. The maximum sample size was determined to be 370 depending on the resources. The sample size for the three districts was determined by probability proportion to the number of householders (Statistical Abstract, 1999). The sample size within districts was selected by probability proportion to the distribution of monthly income groups of the householders available at the DSD offices. The householders were randomly selected within each DSD.

The questions were designed to collect information relevant to the socio economic factors such as the population sector (urban, rural and estate), household income, individual preferences for CNO consumption, level of education, and occupation etc.

\section{Statistical methods}

The data were entered onto an Excel spreadsheet and analyzed using Genstat 5 statistical package. For the analysis only 366 householders were used due to large number of missing values in the records. The response variable is binary (use or non-use of $\mathrm{CNO}$ ) and explanatory variables are categorical and continuous. The generalized linear models with logit link and binomial error (that is, logistic regression models) are fitted separately to each factor as well as taking all the factors together. A linear logistic regression model with a factor, $\mathrm{Xj}$ is

$\operatorname{logit}\left(\mathrm{p}_{\mathrm{i}}\right)=\log \left(\frac{p_{i}}{1-p_{i}}\right)=\beta_{0}+\beta_{1} X^{i}{ }_{\mathrm{j}} \quad \ldots$ (1)

represented as:

$\mathrm{pi}=$ the probability of using $\mathrm{CNO}$ by $\mathrm{a}$ householder in the $i^{\text {th }}$ level of the exposure factor $\mathrm{X}$. Thus

$$
\mathrm{p}_{\mathrm{i}}=\frac{\mathrm{e}^{\beta_{0}+\beta_{1} X_{1}}}{1+\mathrm{e}^{\beta_{\mathrm{o}}+\beta_{1} X_{1}}}
$$

The model with $\mathrm{k}$ exposure factors $(\mathrm{p}=1,2 \ldots \mathrm{k})$ is

$\operatorname{logit}\left(p_{i}\right)=\log \left(\frac{p_{i}}{1-p_{i}}\right)=\beta_{0}+\beta_{1} X_{1}+\beta_{2} X_{2}+\ldots+\beta_{k} X_{k} \ldots(2)$

written as:

$\mathrm{p}_{\mathrm{i}}=\frac{\mathrm{e}^{\eta_{i}}}{1+\mathrm{e}^{\eta_{i}}}$ and $\eta_{\mathrm{i}}=\beta_{0}+\sum_{j=1}^{k} \beta_{\mathrm{j}} X_{j}$

$\beta 0=$ intercept, and $\beta i$ is the effect of $i^{\text {th }}$ variable (or odd ratio). The confidence intervals of the log odd ratios were used to test the significant difference of the use of $\mathrm{CNO}$ between the levels within a factor. 


\section{Results and discussion}

\section{Descriptive statistics for the sample}

The distribution of the sample size between

Table 1. Distribution of sample size between and within two strata

\begin{tabular}{ccccc}
\hline \multirow{2}{*}{$\begin{array}{c}\text { Monthly } \\
\text { Income (in } \\
\text { Rs.) }\end{array}$} & \multicolumn{3}{c}{ Population sector } & Total \\
\cline { 2 - 5 } & Urban & Rural & Estate & \\
\hline$<3500$ & 19 & 20 & 40 & $79(21.6)$ \\
$3500-10000$ & 19 & 40 & 30 & $89(24.3)$ \\
$6000-10000$ & 22 & 28 & 28 & $78(21.3)$ \\
$10000-25000$ & 34 & 2 & 39 & $75(20.5)$ \\
$>25000$ & 27 & 0 & 16 & $45(12.3)$ \\
\hline Total & $121(33.1)$ & $90(24.6)$ & $155(42.3)$ & 366 \\
\hline
\end{tabular}

(The row and column percentages with respect to the total are given in parentheses)

the two strata is shown in Table 1.

In $49.7 \%$ of the samples, the occupation $(49.7 \%)$ was skilled and non-skilled workers (carpenters, plumbers, drivers, etc.). Others were businessmen $(27.6 \%)$, clerical/technical staff $(13.7 \%)$ and professionals $(9.0 \%)$. The majority of those interviewed $(57.4 \%)$ had primary education (up to $9^{\text {th }}$ standard) while $33.0 \%$ and 9.6\% had secondary (up to Ordinary or Advanced Level of General Certificate of Education) and tertiary (at least a degree level) respectively. The size of the household varied from two to ten with a mean of five. The percentage of householders in the sample who use CNO was 91.6 (Table 2).

\begin{tabular}{|l|c|c|}
\hline \multirow{2}{*}{$\begin{array}{c}\text { Population } \\
\text { sector }\end{array}$} & \multicolumn{2}{|c|}{ Percentage of householders } \\
\cline { 2 - 3 } & Use & Non use \\
\hline Urban & 85.0 & 15.0 \\
\hline Estate & 97.8 & 2.2 \\
\hline Rural & 92.0 & 8.0 \\
\hline Total average & 91.6 & 8.5 \\
\hline
\end{tabular}

Table 2. Association between the regions and the use of CNO
Relationship between the individual factors with the use of CNO

\section{Population sector}

The use of CNO was significantly associated with the type of population sectors $\left(\chi_{(2)}^{2}=11.7 ; \mathrm{p}\right.$ $=0.003)$. The confidence interval of the odd ratios confirmed that use of $\mathrm{CNO}$ was significantly higher in the estate sector than in the urban sector. Thus the non-CNO users are significantly higher in the urban sector. There was no significant difference of the use of the $\mathrm{CNO}$ between the rural sector and the urban sector. The percentages of the householders who do not use CNO in the urban sector are almost double the corresponding percentage in the rural sector.

\section{Monthly income}

As the monthly income obtained from the DSD offices had not been updated since 1995, the respondents were asked to specify the average monthly income of the household and those values were used for the analysis. The monthly income of the householders in the sample varied from Rs. 350 to Rs. 180,000 with the mean of Rs. 13,500 and the median of Rs. 7,000. The proportion of using $\mathrm{CNO}$ by the householders having income below Rs. 3,500 was 99\%. The corresponding proportion for the income group of Rs. 3,500 to Rs. 7,000 were $96 \%$. When the monthly income is above Rs.5,000 the percentage of using $\mathrm{CNO}$ was 70 . The fitted logistic model using taking the income as a continuous variable is shown in Fig. 1.

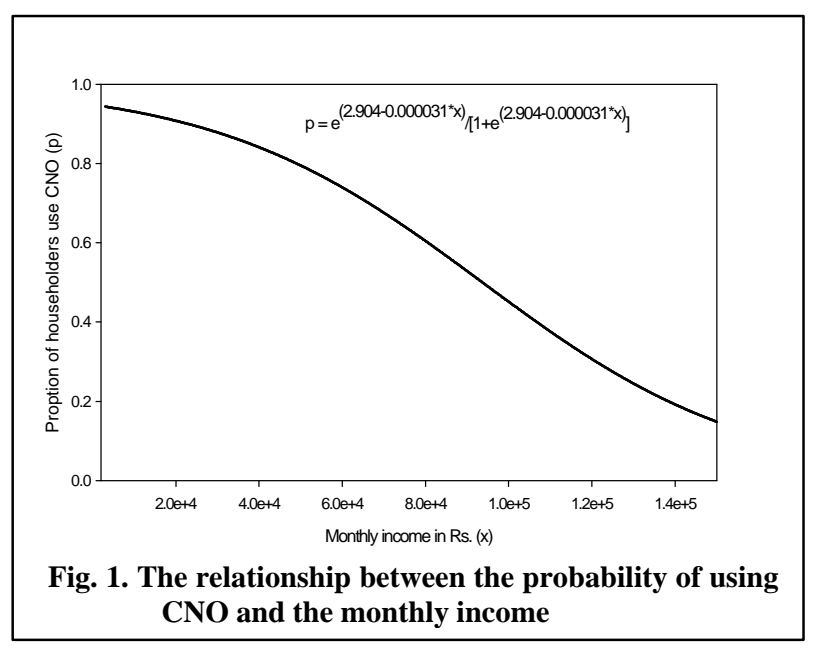


The adequacy of the model was tested using residual checks and half-normal plots (Collet, 1991). Fig. 1 indicates that the probability of using CNO decreases slowly when the income increases up to around Rs. 40,000 per month and thereafter it decreases sharply.

\section{Quality of the CNO}

The percentage of householder who does not satisfy the quality was $76 \%$. The proportion of using CNO between the two levels of consumers' perspectives on quality of CNO (satisfactory and not satisfactory) was marginally significant at the $5 \%$ level. The proportion of using CNO by those not satisfied with the quality of $\mathrm{CNO}$ was $89 \%$ as against $95.4 \%$ who were satisfied with the quality.

The CNO can be obtained either as bottled $\mathrm{CNO}, \mathrm{CNO}$ in bulk (available in barrels or large tins) or by milling own copra. The proportion of non-satisfaction was almost the same $(75 \%)$ in the three types of sources of CNO. The reasons for non-satisfaction were asked from all the respondents.

The oils other than $\mathrm{CNO}$ were grouped into categories. The trade names of sunflower, corn and soya and the trade names of prima, mazola, RBD palmolein, and other brands under vegetable oil were named as 'polyunsaturated' and 'other' oils respectively. The percentages of householders who claimed that the quality of CNO was not in satisfactory condition were 75 , 100 and 80 among the users of CNO, polyunsaturated oils and other oils respectively. The main reason for non-satisfaction of householders was the adulteration of $\mathrm{CNO}$ (Table $3)$.

Table 3. Householders not satisfied about quality of coconut oil

\begin{tabular}{|l|c|c|}
\hline \multirow{2}{*}{$\begin{array}{c}\text { Reason for not being } \\
\text { satisfied about quality }\end{array}$} & \multicolumn{2}{|c|}{ Percentage } \\
\cline { 2 - 3 } & $1^{\text {st }}$ reason $*$ & $2^{\text {nd }}$ reason $*$ \\
\hline Adulterated & 74.5 & 15.2 \\
\hline Can't keep cooked meals & 15.6 & 57.9 \\
\hline Taste & 9.9 & 26.9 \\
\hline Total & 100.0 & 100.0 \\
\hline
\end{tabular}

* Percentages based on the number of respondents only

\section{Education level and occupation}

The use of CNO was significantly associated with educational level of the householder $\left(\chi_{(2)}^{2}=\right.$ 13.2; $\mathrm{p}=0.001)$. The percentage of using $\mathrm{CNO}$ by those having primary education $(96 \%)$ was significantly higher than the corresponding proportion of those having secondary $(87 \%)$ or tertiary (80\%) education. No significant difference was found between secondary and tertiary groups.

The percentages of the use of CNO by the professionals, businessman, clerical staff and skilled and non-skilled workers were 84.8, 86.0, 85.1 and 97.3 respectively. The use of CNO by the skilled and non-skilled workers was significantly higher than other groups, but there was no significant difference among other three groups.

\section{The status of the previous use of CNO}

In the sample, only $86.8 \%$ had used $\mathrm{CNO}$ about five years back. The use of CNO by the householders was significantly associated $\left(\chi_{(1)}^{2}=\right.$ 99.8; $\mathrm{p}<0.001)$ with the status of the previous use of CNO (yes or no). Of the previous users, $98.4 \%$ are using $\mathrm{CNO}$ now. The proportion of using $\mathrm{CNO}$ among those who had not used $\mathrm{CNO}$ in past is $43.8 \%$.

The trend of the percentage of householders who use oil under the three oil categories (described elsewhere) is given in Table 4.

Table 4. Percentage of oil user at two different time periods

\begin{tabular}{|l|c|c|}
\hline \multirow{2}{*}{ Oil category } & $\begin{array}{c}\text { Five } \\
\text { years } \\
\text { back }\end{array}$ & $\begin{array}{c}\text { At the } \\
\text { time of } \\
\text { survey }\end{array}$ \\
\cline { 2 - 3 } & $1^{\text {st }}$ choice & $\begin{array}{c}1^{\text {st }} \\
\text { choice }\end{array}$ \\
\hline CNO & 86.8 & 91.2 \\
\hline $\begin{array}{l}\text { Polyunsaturated } \\
\text { oils }\end{array}$ & 1.9 & 3.2 \\
\hline Other oils & 11.3 & 5.6 \\
\hline
\end{tabular}


Table 4 indicates that the percentage of CNO users has increased from $86.8 \%$ to $91.2 \%$ and the householders prefer $\mathrm{CNO}$ to other edible oils than they did 5 years ago.

Table 5 indicates that the main reason for the use of edible oils is the health. The majority of householders use $\mathrm{CNO}$ as they have been using for years.

Table 5. Reasons for a particular choice of oil (\% of householders)

\begin{tabular}{|l|r|r|c|}
\hline \multirow{2}{*}{$\begin{array}{c}\text { Type of oil used } \\
\text { (Presently) }\end{array}$} & \multicolumn{3}{|c|}{ Reasons for a particular choice } \\
\cline { 2 - 4 } & Tradition & Health & Price \\
\hline CNO & 63.2 & 18.6 & 18.2 \\
\hline $\begin{array}{l}\text { Polyunsaturated } \\
\text { oils }\end{array}$ & 8.3 & 83.4 & 8.3 \\
\hline Vegetable oil & 0.0 & 95.0 & 5.0 \\
\hline
\end{tabular}

\section{Misconception about CNO}

The percentage of householders in the sample who believe that the use of CNO is bad because of cholesterol was 18\% (that is 66 out of 366). Among the users $15.9 \%$ (that is 53 out of 334) believe that $\mathrm{CNO}$ is bad. The analysis (Table 6) showed that the proportion of using CNO by those who do not have misconception about CNO (93.7\%) was significantly higher $\left(\chi_{(1)}^{2}=9.96 ; \mathrm{p}=0.002\right)$ than those who have misconception $(80.3 \%)$. It implies that the percentage of $\mathrm{CNO}$ users can be increased if the misconception on $\mathrm{CNO}$ by the householders can be avoided.

Table 6. Relationship between the misconception of CNO and the use of CNO

\begin{tabular}{|c|c|c|}
\hline \multirow{2}{*}{$\begin{array}{c}\text { Believe that CNO is } \\
\text { bad because of } \\
\text { cholesterol }\end{array}$} & \multicolumn{2}{|c|}{ Percentage of householders } \\
\cline { 2 - 3 } & Use CNO & $\begin{array}{c}\text { Do not use } \\
\text { CNO }\end{array}$ \\
\hline Yes & 80.3 & 19.7 \\
\hline No & 93.7 & 6.3 \\
\hline
\end{tabular}

The survey also found that there was no significant association between the use of $\mathrm{CNO}$ for cooking purposes by the householders and heart disease reported by a member of the household. However, the proportion using $\mathrm{CNO}$ by a householder has slightly reduced (from $91.2 \%$ to $87.5 \%$ ) when a member of the house had reported a heart disease. The tendency to use polyunsaturated oil has increased when a member of house had heart disease.

\section{Identification of significant factors on the use of CNO}

When the effect of each factor on the use of $\mathrm{CNO}$ considered separately, effect of each factor is not adjusted for the effect of other factors. As there are many potential predictor variables it is necessary to consider all factors together. The most suitable method to find out relationship between a dichotomous response variable (use or non-use of $\mathrm{CNO}$ ) with a set of ordinal explanatory variables is the use of linear logistic model described in the equation (2). Due to small sample size and only about $9 \%$ not using coconut oil, it is not possible to consider all the factors into the model at one time. The factors were included into the model sequentially one at a time based on the significance of the deviance of the regression. The household income was included as a continuous variable. The best-fitted model was identified based on the deviance statistic defined as minus twice the log-likelihood ratio between the model fitted and a full model that explains all the variation in the data. As the residual deviance was less than one, the over dispersion did not arise (Collet, 1991). The result of the final accumulated analysis of deviance is given in Table 7. Two- way interaction was significant. 
Table 7. Accumulated analysis of deviance

\begin{tabular}{|c|c|c|c|c|}
\hline Factor & df & $\begin{array}{c}\text { Mean } \\
\text { deviance }\end{array}$ & $\begin{array}{l}\text { Deviance } \\
\text { ratio }\end{array}$ & Chisq pr \\
\hline Income- I & 1 & 17.01 & 17.01 & $<0.001$ \\
\hline $\begin{array}{l}\text { Population } \\
\text { sector - P }\end{array}$ & 2 & 6.02 & 3.01 & 0.050 \\
\hline $\begin{array}{l}\text { Quality of } \\
\text { CNO - Q }\end{array}$ & 1 & 3.84 & 3.84 & 0.050 \\
\hline $\begin{array}{l}\text { Misconception } \\
\text { about CNO } \\
\text { M }\end{array}$ & 1 & 5.26 & 5.26 & 0.022 \\
\hline $\begin{array}{l}\text { Status of the } \\
\text { previous use } \\
\text { of CNO - S }\end{array}$ & 1 & 74.23 & 74.23 & $<0.001$ \\
\hline Residual & 359 & 0.31 & & \\
\hline Total & 365 & 217.07 & 0.59 & \\
\hline
\end{tabular}

The residuals of the final model were checked and found that there was no systematic pattern in the residuals. Table 7 indicate that, when all factors were considered together, the significant factors on the use of $\mathrm{CNO}$ are the status of the previous type oil, the monthly income, misconception about $\mathrm{CNO}$, quality of $\mathrm{CNO}$, and the population sectors. The model can be expressed in the form

$$
\log i t\left(p_{i j k l}\right)=\beta_{0}+\mathrm{I}+\mathrm{P}_{\mathrm{i}}+Q_{j}+M_{k}+S_{l}
$$

where $\beta_{0}$ is a constant and $X_{j}$ is the effect due to the $j^{\text {th }}$ level of the factor $X$. The values of the estimators along with their standard errors are given in Table 8.

Table 8. The properties of coefficients of the fitted logistic model

\begin{tabular}{|c|c|c|}
\hline Parameter & Estimate & S. E. \\
\hline Constant & 5.460 & 1.070 \\
\hline Income & -0.000021 & 0.000095 \\
\hline Population sector - estate & -0.720 & 1.040 \\
\hline - rural & -0.738 & 0.603 \\
\hline Quality & -0.842 & 0.711 \\
\hline Misconception about CNO & 0.314 & 0.560 \\
\hline Status of the previous use of $\mathrm{CNO}$ & -4.399 & 0.641 \\
\hline
\end{tabular}

A test of parallelism identified that the relationship of the proportion of using $\mathrm{CNO}$ and the income between the levels of a given factor was significant only in the factor of the previous use of CNO only. The trend lines for the two levels of the previous use of $\mathrm{CNO}$ are shown in Fig. 2.

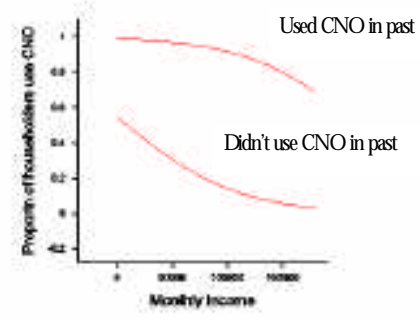

Fig. 2. The fitted model for those who use CMO in past and those who did not use CNO in the past

\section{Rate of oil consumption}

The mean rate of edible oil consumption per person per year was found as 8.38 bottles with a standard error of the mean of 0.23 , irrespective of the type of oil used and other external factors effecting on the use of CNO (Table 9).

Table 9. The rate of oil consumption by the householders (bottles per head per year)

\begin{tabular}{|lcc|}
\hline \multicolumn{1}{|c}{ Type of oil } & $\begin{array}{c}\text { Mean (in } \\
\text { bottles) }\end{array}$ & $\begin{array}{c}\text { 95\% confidence } \\
\text { interval of the mean }\end{array}$ \\
\hline CNO & 8.35 & $7.90-8.90$ \\
Polyunsaturated & 10.14 & $6.28-14.00$ \\
Others & 7.98 & $5.37-10.59$ \\
\hline Mean & 8.38 & $7.92-8.93$ \\
\hline
\end{tabular}

The value obtained in this study is higher than national average of five bottles based on the annual consumer survey (Anonymous, 2001). As the householders do not keep records on the amount they actually used such divergence in 
findings by different studies may be expected. Nevertheless about 25\% householders claimed the rate of oil consumption has increased during the recent past while others claimed that the rate of consumption has reduced. The rate of consumption of polyunsaturated oils was higher than that of CNO. There is a practice of using the same oil repeatedly. This practice was the highest (55\%) among the users of CNO. In fact, the $\mathrm{CNO}$ can be used repeatedly since it contains higher amount of saturated fatty acid (90\%) and is more stable at high temperatures used for frying than other edible oils (Yalegama, personal communication).

\section{Discussion}

A number of points have emerged from this study on edible oil consumption patterns by the Sri Lankan consumers and the factors, which influence the consumers' choices towards $\mathrm{CNO}$ vis-à-vis other edible oils. The findings of this study can be effectively used in planning the strategies for popularizing the use of $\mathrm{CNO}$ among the householders in Sri Lanka.

The proportion of the householders using CNO in the total sample is $91.2 \%$ (Table 2). The proportion using $\mathrm{CNO}$ has been increased by $4.4 \%$ (Table 4) over the last five years irrespective of urban, rural or estate sector, but $75 \%$ of householders claimed that the quantity of CNO used per head per year has declined compared to five years ago. This is an alarming signal to the coconut oil milling industry in Sri Lanka, which caters the total domestic CNO demand. The proportion using sunflower, corn or soya oil (polyunsaturated oils) too has been increased by $1.2 \%$ over the last five years (Table 4). Therefore, it is clear that certain consumers have substituted their edible oil demand with polyunsaturated oils other than $\mathrm{CNO}$.

The logistic regression model (equation 3) provided the best fit for the data set and identified the significantly influential factors on $\mathrm{CNO}$ as (i) the previous brand of oil, (ii) income, (iii) quality, (iv) misconception on $\mathrm{CNO}$ and (v) population sector (Table 7). Of the five variables, the previous type of oil was the most influential variable. Of the householders who used $\mathrm{CNO}$ in the past, $98.4 \%$ use at present, while of the householders who did not use $\mathrm{CNO}$ in the past, $43.8 \%$ use $\mathrm{CNO}$ now. This gives an indication, that a new group of $\mathrm{CNO}$ consumers who did not use CNO in the past has been added in the market. It emphasis that there will be a good potential for $\mathrm{CNO}$ producer.

Income was the second influential variable on the use of CNO. The probability of not using $\mathrm{CNO}$ by a low-income householder was very low. The probability of not using CNO sharply decreased when the income increased above Rs. 40,000 per month (Fig. 1). This suggests that the high-income groups in the country tend to consider $\mathrm{CNO}$ as inferior commodity and may have shifted their tastes and preferences towards other edible oil consumption substituting CNO. This result is consistent with the negative income effect of CNO demand obtained by Samarajeewa and Gunathilake (1999). This implies that with the economic growth of the country and subsequent increases in the per capita annual incomes, further downward trend in domestic $\mathrm{CNO}$ demand are inevitable. Therefore, there is a timely need to promote the CNO consumption in Sri Lanka by implementation of effective marketing strategies to revitalize the domestic CNO industry, which has already been facing a crisis. This could be due to the fact that the highincome householders are more concerned about quality, though there was no significant interaction between quality and income.

The relationship between the probability of $\mathrm{CNO}$ use by a householder and the income in the two levels of status of use of CNO in the past (yes or no) were significantly different. The proportion of $\mathrm{CNO}$ use is decreasing faster for those who have not used $\mathrm{CNO}$ in the past than those who have used $\mathrm{CNO}$ in the past with increasing income as depicted in Fig. 2. It indicates that there is another group of $\mathrm{CNO}$ users, we must concentrate to promote CNO.

The survey found that the main reason for dissatisfaction with the quality of $\mathrm{CNO}$ was adulteration (Table 3 ) and about $80 \%$ were aware 
of how to identify the quality (that is color followed by smell) correctly. Thus it gives a signal to the producers of $\mathrm{CNO}$ that the consumers are more concerned about the quality of $\mathrm{CNO}$, even though they are using it. This gives a valuable message for the $\mathrm{CNO}$ producers to maintain the quality of $\mathrm{CNO}$, which certainly attracts the average consumer. The $\mathrm{CNO}$ consumer would also be willing to pay a competitive price for quality $\mathrm{CNO}$ they purchase if they are available in the market according to the views expressed during the survey. Therefore, marketing of quality assured $\mathrm{CNO}$ with branded names may give a better profit for the $\mathrm{CNO}$ producer. Also this would be helpful in attracting the affluent communities in the society, who already have shifted their choices towards other edible oil consumption.

About $19 \%$ in the sample believe that $\mathrm{CNO}$ is bad for health irrespective of the type of oil they use. Table 6 shows that the corresponding percentage for those who use coconut oil is $16.7 \%$. In other words, $83.7 \%$ of the users of $\mathrm{CNO}$ do not believe that the $\mathrm{CNO}$ is bad for health. Nevertheless only $50 \%$ of the polyunsaturated oils users and $35 \%$ of other oil users claimed that coconut oil is bad for health. In fact Waidyanatha (2001) indicated that a large group of clinicians and nutrition scientists has been unaware of the potential benefits of consuming food containing coconut oil and coconut. Thus it further supports the necessity of a productive campaign on popularizing the use of $\mathrm{CNO}$, revealing the exact health factors on $\mathrm{CNO}$ use.

The percentage using $\mathrm{CNO}$ was significantly lower in the urban sector than in the other two sectors. This is again a negative factor for the $\mathrm{CNO}$ industry, as more and more people are shifting to the urban areas for their living, while there is a continuous shrinkage of the boundaries in the rural sector of Sri Lanka. This leads to further losses of the market share for $\mathrm{CNO}$ in the domestic market, since the urban population sector consists of a considerable number of non$\mathrm{CNO}$ users than the rural and estate population sectors in the country. This may be due to nonavailability of substitute oil for $\mathrm{CNO}$ as compared in urban and rural sectors. However, if we can convince the people to use $\mathrm{CNO}$ there won't be a difference in the pattern of use between population sectors.

\section{Conclusion}

The survey revealed that coconut oil is used by $91.2 \%$ of the householders in Sri Lanka for culinary purposes while edible oils and others use polyunsaturated oils. The percentage of coconut oil users is significantly higher in rural and estate sector than urban sector. The high income and the rapid urbanization are two main factors that influence the householders to shift for edible oil. Irrespective of the type of oil used and the income of the family, almost all householders complain that they are not satisfied with the quality of coconut oil. The main reason for dissatisfaction is adulteration. Majority of the householders have misconception on the use of coconut oil due to health risk, though it has not been proved. There would be better prospects for the coconut oil industry in Sri Lanka by improving the quality and dispelling the misconception among the householders.

\section{Acknowledgement}

The authors are thankful to Prof. R. O. Thattil, Director, PGIA, University of Peradeniya and Dr. S. Samita, Senior lecturer in Statistics, Department of Crop Science, University of Peradeniya for their valuable comments on this paper. We also thank to Mr. S. Rajapakse and Mr. S. D. J. N. Subasinghe of the CRI for their efficient support to conduct the survey.

\section{References}

Anonymous, 1999. Statistical Abstract of the Democratic Socialist Republic of Sri Lanka. Department of Census and Statistics, Ministry of Finance and Planning, 202 pp.

Anonymous, 2001. Annual Report. Central Bank of Sri Lanka, 178 pp. 
Collett, D. 1991. Modelling Binary Data. London, Chapman \& Hall, 369 pp.

Peiris, T. S. G. and Fernando, M. T. N. 2000. The role of coconut industry in Sri Lanka towards the world trend on kernel products. In: The Proceeding of the International Conference on Plantation Crops, Green Park, Hyderabad, India, 21 pp.
Samarajeewa, S. R. and Gunathilake, H. M. 1999. Estimation of demand function for coconut oil - A cointegration study. Trop. Agric. Res. 11: 324-334.

Waidyanatha, U. P. de S. 2001. Coconut and cholesterol - Some hard facts. The Daily News Paper of Sri Lanka, 3 October, 2001. 